\title{
Improved Cashew Planting Material Production in Benin, A Case Study of New Grafting Process
}

\author{
$\left[\right.$ S., Kodjo ${ }^{(1)}$, K., N'Djolosse ${ }^{(1)}$, R., Maliki ${ }^{(1)}$, M. A., Tandjiékpon ${ }^{(2)}$ ]
}

\begin{abstract}
Cashew is an important cash crop in Benin. Currently the average production per hectare is 300$500 \mathrm{~kg}$ i-e $3-5 \mathrm{~kg} /$ tree, which is low compared to other countries like Tanzania with an average productivity of $15-20 \mathrm{~kg} /$ tree. Low yield is mainly due to use of unimproved cashew planting materials. Benin government made efforts to ensure improved planting materials availability. However, improved cashew planting material production remains a big challenge because the use of seeds does not guarantee farmer getting true type cashew planting materials. Grafting technique has been adopted in cashew propagation but low success rates $(50 \%-70 \%)$ in grafting were a limiting factor. Softwood grafting technique has been developed and experimented for promoting cashew propagation materials. But due to low success rate obtained by grafters, many were forced to stop grafting. A new grafting process has been developed which enabled success rates to increase more than $51 \%(55.3 \%$ to 83.6\%). This process includes effective and efficient nursery management mainly rootstocks growing, appropriate sunlight management, appropriate seedlings alignment and grafting process. This paper discuss this simple and low cost new grafting process which needs to be transferred to other grafting operators needing to raise up their success rate.
\end{abstract}

Keywords: Grafting, Planting material, rootstocks, scions.

S., Kodjo

Institut National des Recherches Agricoles du Bénin

(INRAB).

Benin Republic,

\section{K., N'Djolosse}

Institut National des Recherches Agricoles du Bénin

(INRAB).

Benin Republic

\section{R., Maliki}

Institut National des Recherches Agricoles du Bénin

(INRAB).

Benin Republic

M. A., Tandjiékpon

Catholic Relief Service

Benin Republic

\section{Introduction}

Cashew is an important export crop in Benin which ranks second as export crop after cotton. Benin country ranks seventh in the world in terms of cashew nuts production with 90,000 metric tons in 2011 [1].

Benin Strategic Plan for Agricultural Sector Raize (PSRSA, 2010) ranks cashew as one of the 13 major crops which need to benefit of more intervention and improvement. Benin has registered an annual growth rate of cashew nut exports. Cashew nut export increased from 33\% to $40 \%$ of the Benin global national export. There has been an increase in export of raw cashew nut from 36,487 tons in 2001 to more than 116,398 metric tons in 2008 [2]. In Benin cashew nut production comes from six of the twelve regions of the country, i-e Borgou, Atacora, Donga, Zou, Collines and Plateau and is increasingly becoming important socioeconomically and environmentally. More farmers grow cashew and areas planted with cashew were increasing from year to year. However, despite the Government startegies to improve cashew sector and farmers dedication in cashew planting the average yield of cashew nut is 3 to $5 \mathrm{~kg} /$ tree which is very low compared to those obtained in the major producing countries of the world $(15-20 \mathrm{~kg} /$ tree $)$ such as India, Viet Nam, Brazil and Tanzania [3,4]. This low trees yield considerably limits the productivity and production and therefore farmers, processors and traders income and the country as a whole. Efforts have been made to develop improved high yielding cashew planting materials which involved selection of the outstanding high yielding genotypes. Following the identification of the mother trees, it was noted that propagation by seeds does not guarantee the establishment of orchards with homogeneous materials since cashew is highly out-crossing by $70 \%[5,6]$. The results of works carried out upon productivity improvement and spreading of improved planting materials showed that grafting is one of the most appropriate solutions for production and dissemination of improved planting materials in Benin. This was considered the most effective method that could help to disseminate the materials in shortterm and sustainably increase nut productivity in new cashew plantations. To contribute to better productivity of cashew, GIZ in collaboration with Benin National Agricultural Research Institute (INRAB) in 2011 initiated a cashew varietal improvement project. The program introduced grafting techniques (soft-wood) and nurseries with the aim to provide producers with true-to-type of high yielding planting materials. Fourteen grafting operators were trained with ACi financial support since 2011. However, after two years of practice, grafting success rate remained globally low (59.4\%), [7] and called for more improvement. This paper discusses the efforts made in order to identify factors that contribute to improved grafting success rate in Benin. 


\section{Methodology and approach}

This work was conducted from 2012 to 2015 in 14 nurseries, located in 11 districts namely, Djidja, Ouessè, Glazoué, Savè (Zou- Collines i-e Central Region), Bembèrèkè, Parakou, Nikki, Tchaourou (Borgou i-e North- Est Region), Ouaké, Djougou and Kouandé (Atacora-Donga i-e North-Western Region) in Benin. Substrate was prepared by mixing one barrow of sandy + loam + clay soil with $3 \mathrm{~kg}$ of NKPSB fertilizer (14-23-14-5-1). Seeds used were clean, healthy and uniform size. Floating test helped to select the best seeds for planting. The selected seeds are planted (in the poly bag) with the scar attached to the fruit facing upwards and pushed slightly down $2-3 \mathrm{~cm}$ deep into the medium and covered with soil. Water supplying were efficiently conducted in all nurseries and depends on the weather (too much watering was avoided). Rootstocks establishment took 6-8 weeks before grafting process.

The maximum days number for rootstock to be grafted to realize high graft success lays from 45 to 60 days. However, when rootstocks have not reached pencil size after 60 days, grafting can occur after 80 days old. Scions preparation (by removing/cutting leaves from buds/scions) is acheived 7 to 12 days before harvesting on seleted mother trees in farmers existing cashew plantations or in scion banks established by Benin National Agricultural Research Institute ( INRAB).

For most grafting operators, scions were harvested early in the morning or late in the evening the grafting day or the day before or at least 48 hours before grafting process. Two grafting techniques were investigated (single slot and veneer or side-grafting). After grafting process, young grafted plants were maintained by tap removing after $10-15$ days after young leaves emission. After grafting, plants growing and death were observed after 26, 41 and 79 days.

The observations in the experimental nurseries imphasized several factors or data including: - sunlight management above the nursery through net management (rolling and deployment) - Seeds Sanitary quality for rootstocks production (minimum humidity)

-Grafting period in the year, - Spatial rootstocks arrangement on the planks, - Grafting time (morning, afternoon and evening) - The applied grafting technique (single slot, veneer or side-grafting);

- The management or monitoring and maintenance of grafted plants (suckering);

- Poly caps installation and removing.

\section{Results and discussion}

After 2 years of data collection and analysis from 13 operational nurseries (2013-2014) and grafting operators skill in their activities, results suggested selection of a set of practices and procedures that date back significantly grafted seedlings recovery rate. The set of practices and procedures can be summarized as follows:

The graph below suggested that the highest recovery rates were obtained by Ouake's nurseries (90.6\%). The lowest results were obtained respectively at Bembereke and Glazoue nurseries with 34.1 and $42.4 \%$ of recovery rate.

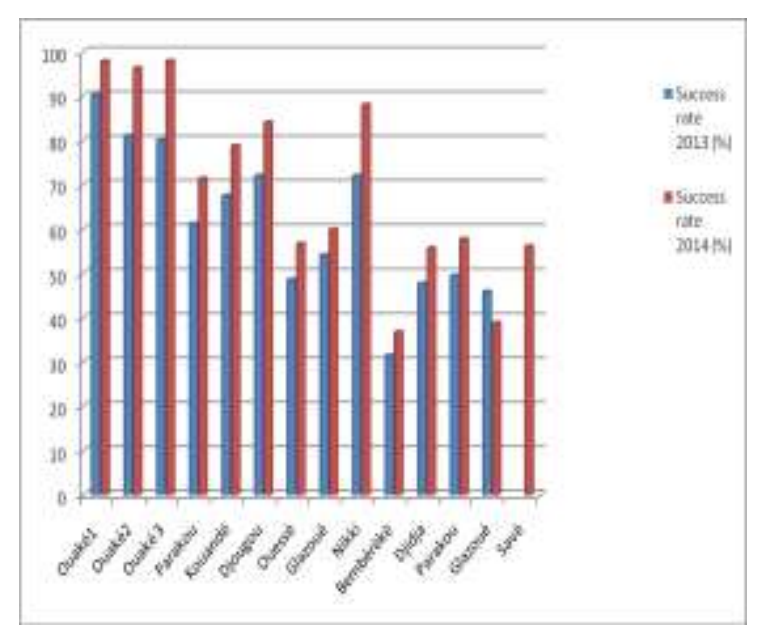

Figure 1: Grafting success rate per nursery

However, a deeper analysis of the data analysed suggested concerning data collected:

\section{A. Sunlight management above the nursery}

Some nurseries notably those of Ouake imporved sunlight management above the nurseries.

The graph below shows success rates distribution between the nurseries applying Improved Sunlight management (Isl) and those who didn't change their practices indicated (Usl) : Usual sunlight management. 


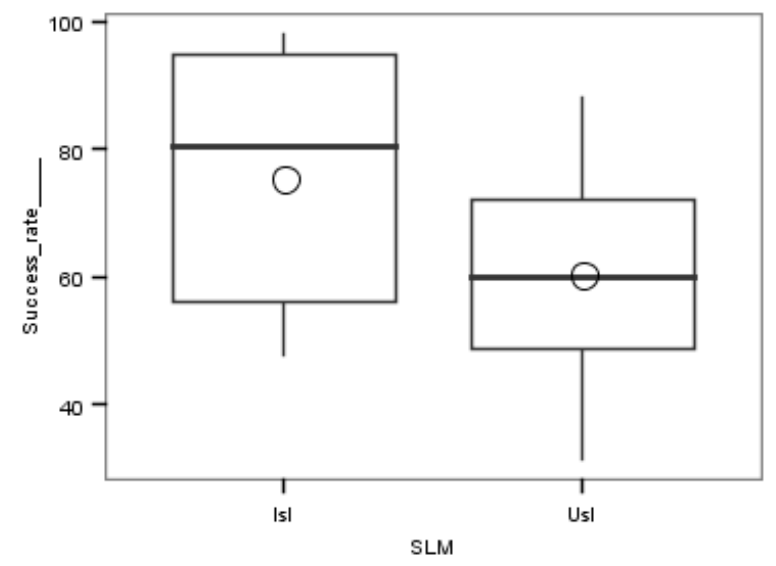

Figure 2: Box plot of grafting recovery rate and Sunlight Management

Data analysis suggested significant differences between nurseries' grafting recovery rate $(\mathrm{P}<0.04575)$ at $95 \%$ level of confidence where sunlight management was improvement (Isl=75.4\%) and those where sunlight was not changed (Usl=60.1\%). This result revealed that sunlight above the nursery should be differentially managed according to seedlings development stages and rootstocks development after grafting process. Indeed a stronger brightness promotes development in height and rootstock diameter, which shortens the breeding time of the seedlings.

However, excessive rootstocks stay under shade house generates a withering of seedlings which could lengthen the time of breeding rootstocks. The average duration of the breeding rootstocks is average 60 days throughout the implementation area of this experiment. Thus, management of light includes a winding or rolling shade net during the maximum of the raising period rootstocks. This net can be deployed just after the grafting of young rootstocks.

This rootstocks breeding duration complies (when the net is well managed) with that stated by $[5,6]$. The duration of rootstocks rearing substantially extends when the net is kept constantly above the seedling. This extension can range from 15 to 30 days beyond the required standards. These results have also been stated by [7].

\section{B. The spatial arrangement of rootstocks plank}

As far as this factor is concerned, analysies chowed a significant difference $(\mathrm{P}<0.004368)$ betweem the nurseries.

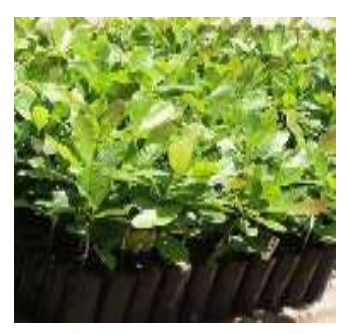

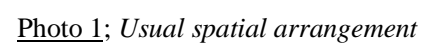

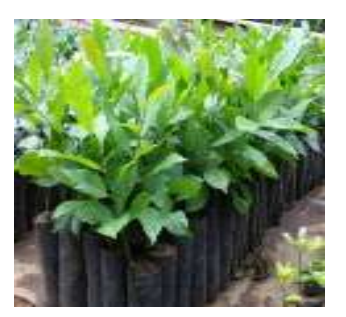

Photo 2; Improved spatial arrangement (recommended)
The average success rate for those applying techniques linked to Improved spatial arrangement of the seedlings (Isa $=81.33 \%$ ) when the others not applying this technique have a low level of success rate $(\mathbf{U s a}=59.29 \%)$ at $95 \%$ level of confidence.

In fact, this technique helps to minimize at strick grafting stress on seedlings or at least to avoid out roots chocks and shoving seedling the grafting day. It has been observed that seedlings/rootstocks arrangement in rank of 6 to 7 pots per board is ideal to make easy the grafting process. Thus, grafters seat along the board on a stool to operate (grafting) without moving the plants.

On another hand, this way to graft help advantageously to reduce seedlings stress before grafting operation. Also time expense is seriously saved during grafting operations. The grafting rate is greatly increased of $+37.7 \%$. The grafters using this technique displayed relatively scores 1.4 to 2 times per time unit in terms of number of plants grafted compared to conventional arrangement. The success rate gained through this arrangement approximately $+37.7 \%$ of recovery rate. Grafters using these grafting way are around 80.1 to $90.3 \%$ each (Means $=81.33 \%$ ) of success rate while the others score average $59.29 \%$ of success.

The two photos above show how cashew seedling should be arranged to increase grafting speed and recovery rate.

\section{The applied grafting technique (single slot, veneer or side-grafting)}

Having a look on this ^parameters, the observations and analyses by Analyses of Variance (ANOVA) showed a high significant difference $\left(\mathrm{P}<2.336 * 10^{-05}\right)$ between success rates of grafters processing single slot grafting (55.4) and 
those applying side or veneer grafting (83.6\%). Single slot grafting technique has been teached to grafters during phase I of iCA and applied by most of thems. However an adaptation was experimented as veneer/side grafting. This technique in fact, allows having a larger contact surface between the cambium of the rootstock and the scion. Therefore, response is a best recovery rate of the grafted seedlings on all nurseries which practiced that in comparison with single slot. One can conclude that this type of grafting leads to better recovery rates in Benin conditions. The same results were observed on the field for top-working operations granted while implementing GIZ /ACi Matching Fund project by Cashew Regional Producers Union (URPA) of Borgou-Alibori from 2013 to 2014 in Benin [7].

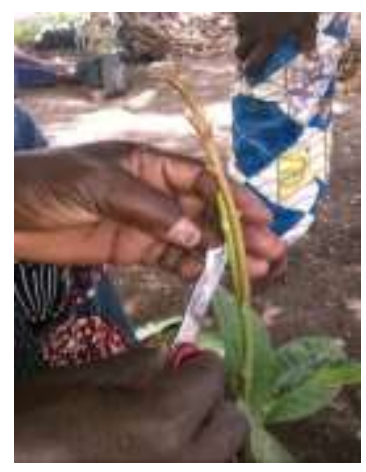

Photo 3; Single slot grafting

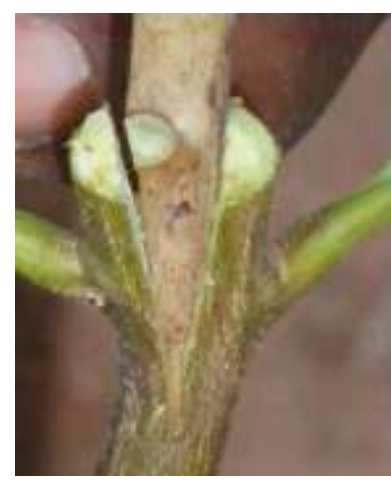

Photo 4; Side grafting technique
As far as the other observations in the nurseries are concerned, it has been possible to understand:

\section{The most suitable grafting period in Benin}

In Benin the most suitable grafting period lays from March to April, and in the worst case May. If specific conditions occurring at this moment, the nursery should compel go beyond this period and it is important to diligently identify, analyze them and provide appropriate solutions [5].

\section{E. Sanitary quality of seeds for rootstocks production (minimum humidity)}

Experiments linked to sanitary quality were conducted aiming to assess water, temperature effect and seed soak time cashew (Anacardium occidentale L.) on germination [7]. This was a preliminary study for the development of method to fight against cashew bacterial caused by Xanthomonas axonopodis.

Results obtained showed that temperatures $60^{\circ} \mathrm{C}, 70^{\circ} \mathrm{C}$ and $80^{\circ} \mathrm{C}$ induced a germination rate of $50 \%$ at the $10^{\text {th }}$ day after sowing. At the end of 16 days after germination with seedling emergence, rate ranged from 83 to $94 \%$ for the $40^{\circ} \mathrm{C}$ to $70^{\circ} \mathrm{C}$ regardless of the seed soak time. At room water temperature, one will require soaking seeds for at least 25 minutes to obtain a germination rate more than $80 \%$. Only the seeds soaked for 10 minutes have germinated when the water temperature is $80^{\circ} \mathrm{C}$.

All this suggests that we need to deal with dry seeds and with adequate humidity to drive without nursery prejudice with satisfactory results.

The steps of the flotation test known as - choosing medium sized seeds, - pouring seeds into a bucket of clean water, - removing seeds floating on the surface because they will not germinate well and soaking for 24 hours in water submerged seeds to enable them to absorb water have to be observed by the same way $[5,6]$.

\section{F. Grafting time}

The ideal time for grafting observed is early in the morning between 7: am and 10:30 and late in afternoon from 3:00pm to 18: pm i.e. 6:30 duration per day. This term does not change substantially with the new technique. However, since the grafters don't move a lot and therefore interfere less in the grafting, they are able to make better use of their time and can reach 7: 30 to 8 hours work per day.

\section{G. The management / monitoring and maintenance of grafted plants (suckering)}

Follow-up work and monitoring of seedlings after grafting does not significantly vary according to the content of the two grafting techniques. It still should be noted that regular care of 3 days for removing continuously greedy new and lateral shoots developing below graft union should be essential until they stop developing.

Water supply also must also be realized with great care. All this helps to significantly increase the survival rate of seedlings in nurseries that participated to the trials.

These few activities are required: sprouting sign - after $2-3$ weeks of grafting check breaking of the apical bud and inspect for disease and pest symptoms and spray when necessary. If growth is observed, cap removing is needed when young leaves are touching the tip of the cap after $6-8$ weeks remove binding tape ensuring of complete wound healing [8].

\section{H. Poly caps installation and removing}

Monitoring or management in polyethylen caps removing (progressive removal of caps at 3-4 leaves) followed by complete removal when the leaves come to be totally opened are steps to be taken with great care. The grafted materials should be monitored for the first 21 days (once every two days) until the apical bud sprouts. The shoots that develop below the graft union must be removed as they appear until they stop coming. Shoots developing around the stump should also be removed. Spraying with appropriate chemical should be done when there pests and diseases infestation appear.

\section{Conclusions, Recommendations and Implications}

These adaptations packet implemented were assessed with all the grafters participating to the experiments. They mostly recognized the prowess of the new grafting process. For those who remained in the grafting sub-sector, they are changing their grafting approach one hand but also improve care skill for nurseries management.

It should be desirable to a wider dissemination of this new package in other countries or regions where success rates still remain relatively low. Adopting this new grafting process should help grafting activities and change practitioners into true entrepreneurs who benefits from their investments. Disseminating this grafting process should enable grafters who are leaving the sector to come back. They should therefore get more cash $(+51 \%)$ from their 
investments. Raising grafting success rate in Benin will enable to speed the new plantations establishment and improve in short terms productivity of new orchards and by the way gross national income of the country.

\section{Acknowledgment}

GIZ-BMZ, BLGF, Cocoa Research Institutions of Ghana (CRIG), MOFA, INRAB, Benin-Nursery operators, Benin Rural extension services.

\section{References}

[1] ACA,, "Along the chain;, Promoting the comptitiveness of African cashew,', $7^{\text {th }}$ African Cashew Alliance (ACA)-African Cashew Initiatives, Conference (ACi), Cotonou, 2012

[2] PAC,. 'Evolution du trafic marchandises: périodes 1999 à 2008,' 2009.

[3] P. A. L. Masawe, "Consultancy Report on Cashew Improvement," Programme for Selected West African Countries (Benin, Burkina and Côte d'Ivoire). GIZ/iCA. 2010., 54p.

[4] A. Tandjiékpon, "'Analyse de la chaîne de valeurs du secteur anacarde du Bénin,' 'GiZ iCA, 2010, 64 p.

[5] P. A. L Masawe, "Aspect of breeding and selecting improving cashew genotypes (Anacardium occidentale L.), ' Ph. D. Thesis, University of Reading, UK, 1994.

[6] E. E. Mneney, S. H. Mantell, and M. Bennett, "Use of random amplified polymorphic DNA (RAPD) markers to reveal genetic diversity within and between populations of cashew (Anacardium occidentale L)', Journal of Horticultural Science and Biotechnology 76: 375-383, 2001

[7] K. N'djolosse, S Kodjo,. et I Moussa,. ' 'iCA. 1er semestre 2014,", 2014, 9p.

[8] J. Yeboah, "Grafting and Top working Technique,". CRIG, 2015. 